\title{
UMA ORDEM ECONÔMICA JUSTA E EQUILIBRADA: O ATIVISMO JUDICIAL EM PROL DA VALORIZAÇÃO DO TRABALHO HUMANO
}

\author{
AN ECONOMIC ORDER THAT IS FAIR AND BALANCED: JUDICIAL ACTIVISM ON \\ BEHALF OF THE VALORIZATION OF HUMAN WORK
}

Gabriela Eulalio de Lima

\begin{abstract}
Mestre em Direito com a linha de pesquisa Empreendimentos Econômicos, Processualidade e Relações Jurídicas pela Universidade de Marília - UNIMAR (2016). Especialista em Direito Material e Processual do Trabalho pelo Centro Universitário de Rio Preto - UNIRP (2015). Graduada em Direito pela Universidade do Estado de Minas Gerais - UEMG, campus de Frutal/MG (2010). Autora do livro "O Consumo Colaborativo no Contexto da Sociedade Líquida: uma análise sociológica, econômica e jurídica" (2017).

Coordenadora de curso de Graduação em Direito. Associada do Conselho Nacional de Pesquisa e Pós-Graduação em Direito - CONPEDI desde 2014. Avaliadora de periódicos

Qualis A1, A2 e B1. Advogada regularmente inscrita na OAB/MG n. ${ }^{\circ} 138.790$ desde

2012. Bolsista na qualidade de pesquisadora, pela Fundação de Amparo à Pesquisa do Estado de Minas Gerais - FAPEMIG, com o trabalho de iniciação científica "Dignidade da Pessoa Humana sob a Incumbência do Estado" (2009/2010).

E-mail: gabrielaeulalio.adv@ hotmail.com
\end{abstract}

Lourival José de Oliveira

Doutor em Direito das Relações Sociais PUC-SP (1999), São Paulo/SP. Docente dos Programas de Doutorado e Mestrado em Direito da Universidade de Marília - UNIMAR,

Marília/SP. Docente do Curso de Graduação da Universidade Estadual de Londrina UEL, Londrina/PR. Docente de vários Cursos de Especializações em Direito; advogado em Londrina. E-mail: lourival.oliveira40@hotmail.com

Recebido em:23/05/2017 Aprovado em: 27/10/2017

RESUMO: Partindo do prisma kantiano que revela a pessoa humana como um valor absoluto e insuscetível de coisificação, a pesquisa dedicou ao estudo da valorização do trabalho humano como um dos fundamentos da ordem econômica constitucional, tomando por base o método dedutivo de análise - com levantamento bibliográfico multidisciplinar. Apontou-se também a nova dinâmica apresentada pelo constituinte de 1988, que estabeleceu um sistema capitalista desmaterializado do conceito puro, apontando uma lógica existencial da ação estatal efetiva, mirando assegurar a concretização dos direitos e garantias fundamentais, demandando do operador do Direito uma interpretação refinada no mesmo compasso das prioridades finalísticas estabelecidas na norma; a partir dessa primeira percepção é que surge o ativismo judicial, como o fenômeno jurídico disponível, usado para propor efetividade na revelação da valorização do trabalho humano na ordem econômica, assegurando à norma constitucional a eficácia apresentada pelo constituinte, rematando um cenário econômico justo, equilibrado e desenvolvido em consonância com a ordem social.

Palavras-chave: Ativismo judicial; Capitalismo; Dignidade humana; Ordem Econômica; Valorização do trabalho. 


\begin{abstract}
Tarting from the prism kant that reveals the human person as an absolute value and insuscetível of objectification, the research devoted to the study of the appreciation of human labor as one of the foundations of the economic order of the constitution, on the basis of the deductive method of analysis with a literature review, multidisciplinary. Pointed out also the new dynamics presented by the constituent assembly of 1988, which established a capitalist system, dematerialised from the neat concept, pointing out a logical existential action of the state effective, aiming to ensure the implementation of fundamental rights and guarantees, calling for the operator of the Right interpretation refined in the same compass of the priorities related to as defined in the standard; from this first perception is that the judicial activism, as the legal phenomenon available, used to propose effectiveness in the revelation of the appreciation of human labour in the economic order, ensuring the standard of constitutional effectiveness presented by the constituent, striking an economic scenario fair, balanced and developed in line with the social order.
\end{abstract}

Keywords: Judicial activism; Capitalism; human Dignity; Economic Order; Appreciation of the work.

SUMÁRIO: Introdução; 1 A pujança da dignidade da pessoa humana enquanto princípio constitucional; $1.1 \mathrm{O}$ princípio da dignidade da pessoa humana e suas implicações para o Direito do Trabalho; $1.2 \mathrm{O}$ valor do trabalho humano e a existência digna; 2 A Ordem Constitucional Econômica de 1988; 3 A gravitação da valorização do trabalho humano na Ordem Econômica Constitucional; $3.1 \mathrm{O}$ ativismo judicial; Considerações finais; Referências Bibliográficas.

\title{
INTRODUÇÃO
}

A pesquisa em tela visa debater o princípio da valorização do trabalho humano como um dos fundamentos da ordem econômica constitucional, em busca do seu alcance justo e equilibrado, revelando o modelo do sistema capitalista alicerçado na Constituição da República com um viés social, conclusão que parte da importância destinada ao valor da dignidade humana do trabalhador enquanto indivíduo e membro da sociedade, demonstrando o dever do Estado de intervir nas relações de trabalho e na economia, contrapondo-se a ideologia predominante em um sistema capitalista puro ou clássico, em que se identifica a presença de apenas duas classes burguesia e proletariado - com a dominação da primeira sobre a segunda à sombra de um Estado inativo.

A evolução do capitalismo puro para o de finalidade social revela a passagem do Estado Liberal para o Estado Social, marcando a necessidade da ingerência estatal na ordem econômica, deixando a economia ou as relações econômicas de serem operadas livremente; propondo ao Estado a responsabilidade por este núcleo, que ao regulá-lo reveste-se do dever de primar pelo equilíbrio e equidade nas relações sociais, assegurando a integridade da ordem social.

A problemática do trabalho aloja-se na necessidade de despontar a relevância da valorização do trabalho humano (artigo 170, caput, do Texto Constitucional), que aventada pela dignidade da pessoa humana como um dos fundamentos da República (artigo $1^{\circ}$, IV), erige-se como o princípio fundamental basilar para o desenvolvimento do cenário econômico nacional enquanto motivação ativa da própria ordem econômica, a qual tem por fim assegurar a todos uma existência digna, conforme os ditames da justiça social, ressalvados entre outros princípios, a função social da propriedade e a busca pelo pleno emprego (incisos III e VIII do artigo 170), que surgem uma condição contraposta a permanência e a reprodução de práticas de superexploração da mão de obra humana. Destaca-se que é através de condições mais dignas de trabalho que será possível atingir uma ordem econômica equitativa e nivelada, em que a exploração não será sobreposta a pessoa do obreiro e a pura prestação do trabalho humano. 
A investigação refletirá a responsabilidade da empresa no aspecto da função social, despontando-a como instrumento ativo, usado para proporcionar condições de dignidade aos indivíduos/trabalhadores através da busca do pleno emprego, de forma que não se vigore uma relação unilateral de trabalho, com a sustentação amplificada do pilar econômico da sustentabilidade (ELKINGTON, 2012, p. 20.), cujos benefícios sejam desfrutados apenas pelo setor empresarial.

Contudo, não obstante a função desempenhada na norma e o papel incumbido à empresa, o núcleo do estudo justifica-se em demonstrar a importância do ativismo judicial na execução da intervenção estatal nas relações de trabalho, com vias a garantir um modelo econômico cujas bases estejam fundamentadas na valorização do trabalho humano sob o processo hermenêutico, adequando o Texto Constitucional à busca de uma ordem econômica justa e equilibrada em conformidade ao modelo vigente do sistema capitalista.

Destarte, suscitando como possíveis resultados, a pesquisa propõe demonstrar os resultados da atuação do Estado Social intervencionista por meio do ativismo judicial para que a ordem econômica alcance a efetividade na revelação da valorização do trabalho humano, assegurando à norma a eficácia sugerida pelo constituinte, rematando num cenário econômico equitativo, balanceado e desenvolvido num processo harmônico com a ordem social.

Na confecção do trabalho utilizar-se-á o método não empírico e dedutivo e como forma de elucidação, será realizado um levantamento bibliográfico multidisciplinar com vias a apresentar o ativismo judicial num prisma de compreensão mais fidedigna acerca da discussão suscitada.

\section{A PUJANÇA DA DIGNIDADE DA PESSOA HUMANA ENQUANTO PRINCÍPIO CONSTITUCIONAL}

Fundamentalmente, faz-se importante apresentar uma reflexão acerca do vigor dos princípios numa visão amplificada - esses nem sempre foram sopesados no ordenamento como normas jurídicas, isso em razão do receio da insegurança que podia derivar do uso deles. Desse modo, aceitar a aplicação da gama principiológica seria o mesmo que suscitar a ordem jurídica a uma instabilidade que não era admitida dentro de um sistema jurídico fechado.

Anterior ao Texto Constitucional de 1988, o Decreto-Lei n. ${ }^{\circ} 4.657$, de 4 de setembro de 1942 - Lei de Introdução às normas do Direito Brasileiro, trazia no seu artigo $4^{\circ}$, uma concepção secundária para a aplicação dos princípios gerais do direito. (BRASIL, Decreto-lei n. ${ }^{\circ} 4.657$, de 4 de setembro de 1942, art. $4^{\circ}$ )

A função do vigente artigo $4^{\circ}$ da Lei de Introdução às Normas do Direito Brasileiro para o sistema jurídico nacional, é apresentar métodos de coerência para o Direito, destacando que na época que foi redigido, prevalecia o entendimento de que a analogia, os costumes e os princípios gerais do Direito deveriam ser invocados na exata ordem em que foram alocados no dispositivo. Logo, os princípios só seriam invocados quando não houvesse regra específica para o caso concreto, hipoteticamente prevista para situações análogas e quando não houvessem práticas reiteradas e geradoras do sentimento de obrigatoriedade.

Póstuma a promulgação da Lei de Introdução às Normas do Direito Brasileiro, o legislador brasileiro, com a promulgação da Lei Federal n. ${ }^{\circ}$ 5.172, de 25 de outubro de 1966 que dispõe sobre o Sistema Tributário Nacional e institui normas gerais de direito tributário aplicáveis à União, Estados e Municípios -, também fez referência a aplicação dos princípios na interpretação e na integração da legislação tributária para os casos em que for ausente disposição expressa, indicando os princípios gerais de direito tributário e os princípios gerais de direito público, respectivamente nos incisos II e III do artigo 108, seguindo estritamente a ordem estabelecida no texto do citado artigo. (BRASIL, Lei n. ${ }^{\circ}$ 5.172, de 25 de outubro de 1966, Art. 108) 
Ronald Dworkin e Robert Alexy ao arrazoarem o tema princípios, concluíram que deveriam ser ponderados como verdadeiras normas jurídicas e por isso, estar disponíveis no ordenamento jurídico ao lado das regras. Nesse propósito, Ronald Dworkin referenciado por Humberto Ávila: "Dworkin sustenta que os princípios, ao contrário das regras, possuem uma dimensão de peso que se exterioriza na hipótese de colisão, caso em que o princípio com peso relativo maior se sobrepõe ao outro, sem que este perca sua validade." (DWORKIN apud ÁVILA, 2004, p. 43)

Já Robert Alexy desponta os princípios como mandados de otimização:

[...] os princípios são comandos de otimização que se caracterizam pelo fato de que eles podem ser atendidos em diferentes graus e o grau de cumprimento devido depende não só sobre as possibilidades legais e reais existentes. O escopo de possibilidades legais é determinado pelos princípios e regras oposto.

Em vez disso, regras são regras que só podem ser cumpridas. Se uma regra é válida, em seguida, fazer exatamente o que ela necessário, nem mais nem menos. Portanto, as regras contêm determinações no âmbito do fatídico e juridicamente possível. Isto significa que a diferença entre régias e princípios é qualitativa e não por sua vontade. Toda norma ou é uma regra ou princípio. ${ }^{1}$ (ALEXY, 1993, p. 86)

Ronald Dworkin e Robert Alexy foram essenciais para que os princípios passassem a ser lançados no ordenamento jurídico como normas que preceituam o Direito com mais magnitude, alcançando as probabilidades jurídicas e fáticas possivelmente existentes.

Atualmente a Constituição da República conta com uma ordem principiológica definida que privilegia a aplicação de princípios específicos de interpretação, buscando o alcance do núcleo essencial da norma constitucional e condicionando que as limitações convencionais de interpretação sejam superadas. Para tanto, isso não implica na renúncia do método clássico subsuntivo da regra e dos meios clássicos da hermenêutica, que se apresentam como elementos insuficientes.

Apesar disso, essa ótica sobre os princípios nem sempre prevaleceu; por muito tempo a interpretação dos princípios esteve vinculada a um modelo fechado, reduzida à interpretação dos operadores do Direito a letra da Constituição e aos métodos formalizados. O formato contemporâneo, apresenta uma normatividade aos princípios sob o sopesamento dos valores e da necessidade da ponderação desses, bem como revela o princípio específico da relatividade como um método de ressignificação aos direitos e as garantias fundamentais, de modo a não considerálos absolutos, justamente por encontrarem seus limites nos direitos garantidos igualmente na Carta da República.

O Texto de 1988 embalado por um movimento favorável à ordem principiológica, introduziu no seu corpo uma magnitude de princípios, elevando sobremaneira a importância do princípio da Dignidade da Pessoa Humana, que passou a ser interpretado como o sustentáculo da gama de direitos e garantias fundamentais, firmando o seu valor em grau acentuado também para a ordem econômica - é o que pode se observar no seu destaque como um dos seus fundamentos, apresentando a valorização do trabalho humano.

\footnotetext{
${ }^{1}$ Texto original: [...] los principios son mandatos de optimización que están caracterizados por el hecho de que pueden ser cumplidos en diferente grado y que la medida debida de su cumplimiento no sólo depende de las posibilidades jurídicas y reales existentes. El ámbito de las posibilidades jurídicas es determinado por los principios y reglas opuestos.

En cambio, las reglas son normas que sólo pueden ser cumplidas ono. Si una regla es válida, entonces de hacerse exactamente lo que ella exige, ni más ni menos. Por lo tanto, las reglas contienen determinaciones en el ámbito de lo fáctica y jurídicamente posible. Esto significa que la diferencia entre regias y principios es cualitativa y no de grado. Toda norma es o bien una regla o un principio.
}

Revista de Direito Brasileira | São Paulo, SP | v. 19 | n. 8 | p. 221 - 237 |Jan./Abr. 2018 
Nessa linha, na sequência o artigo discutirá a importância do princípio da dignidade no campo do Direito do Trabalho de forma específica.

\subsection{O Princípio da Dignidade da pessoa humana e suas implicações para o Direito do Trabalho}

O constituinte de 1988 preocupou-se sobremaneira com a pessoa humana; eis que já no Preâmbulo da Carta Magna a apresenta como o centro do ordenamento jurídico brasileiro de valor essencial. (BRASIL, Constituição da República Federativa do Brasil de 1988, Preâmbulo)

Contudo, é no artigo $1^{\circ}$, inciso III, que a dignidade da pessoa humana é destacada como um dos fundamentos da República Federativa do Brasil e do Estado Democrático de Direito; seguindo a leitura do artigo em tela, os incisos II e IV apontam a referência também a cidadania e aos valores sociais do trabalho e da livre iniciativa, respectivamente.

Abrangida como princípio, fundamento e objetivo do Estado Brasileiro, Ingo Wolfgang Sarlet prescreve a definição do conceito de dignidade da pessoa humana como sendo:

[...] a qualidade intrínseca e distintiva reconhecida em cada ser humano que o faz merecedor do mesmo respeito e consideração por parte do Estado e da comunidade, implicando, neste sentido, um complexo de direitos e deveres fundamentais que assegurem a pessoa tanto contra todo e qualquer ato de cunho degradante e desumano, como venham a lhe garantir as condições existenciais mínimas para uma vida saudável, além de propiciar e promover sua participação ativa e co-responsável nos destinos da própria existência e da vida em comunhão com os demais seres humanos. (SARLET, 2007, p. 62)

Dado esse primeiro exame, já é possível perceber que a Carta da República revela ao sistema jurídico brasileiro uma função efetiva para a valorização do indivíduo, elevando sua dignidade e seus direitos de trabalhador ao status de direitos fundamentais, garantidos no seu núcleo essencial.

Gabriela Delgado argumenta sobre a necessidade de concentrar um sistema de valores como diretriz do Estado Democrático de Direito: “[...] no desempenho das relações sociais, em que se destacam as trabalhistas, deve ser vedada a violação da dignidade, o que significa que o ser humano jamais poderá ser utilizado como objeto ou meio para a realização do querer alheio." (DELGADO, 2006, p. 206)

Veja-se que a garantia da existência digna se valida com a ponderação da valorização do trabalho humano; não há como dissociar a realização da dignidade da pessoa humana da mão de obra do trabalhador, ao passo que qualquer violação aos direitos sociais, escalonados entre eles os justrabalhistas, afetaria diretamente a essência da dignidade. Contribuindo para esse ponto da discussão, José Felipe Ledur:

[...] a realização do direito ao trabalho fará com que a dignidade humana assuma nítido conteúdo social, na medida em que a criação de melhores condições de vida resultar benéfica não somente para o indivíduo em seu âmbito particular, mas para o conjunto da sociedade. (LEDUR, 1998, p. 98)

O Autor segue justificando a afinidade do Princípio da Dignidade da Pessoa Humana e do acesso ao trabalho digno:

[...] as normas que garantem os direitos econômicos devem assegurar, de sua parte, o direito a um nível de vida decente, como expressão e realização desse princípio fundamental. [...] como primeiro princípio dos direitos fundamentais, 
ele (o princípio da dignidade da pessoa humana) não se harmoniza com a falta de trabalho justamente remunerado, sem o qual não é dado às pessoas prover adequadamente a sua existência, isto é, viver com dignidade. (LEDUR, 1998, p. 103)

Com efeito, não há como ignorar a dependência do Direito Trabalho ao princípio constitucional da dignidade da pessoa humana, valendo-se do significado intrínseco para resguardar ao obreiro o direito de ter através do seu trabalho os recursos imprescindíveis na busca do processo de dignificação, alcançáveis por meio das condições laborativas dignas à essência humana, a fim de garantir uma exploração que não extrapole os limites convalidados em lei e aos ditames constitucionais, concretizando finalmente o anseio da ordem econômica mais equitativa e compensada.

\subsection{O valor do trabalho humano e a existência digna}

Observou-se até aqui há uma relação entre a existência digna do trabalhador, a valorização do trabalho humano e a ordem econômica. Nesse ponto, para tanto, releva-se destacar que esse elo só é referenciado quando o conceito de dignidade previne que a pessoa humana seja utilizada como meio para que um fim seja atingido, dando ao indivíduo um sentido final em si mesmo, não se reconhecendo nenhuma suposição de "coisificação" da pessoa.

Immanuel Kant nessa linha assevera que: “[...] os seres racionais estão submetidos a um imperativo categórico que determina que cada um deles jamais trate a si mesmo ou aos outros simplesmente como meios, mas sempre simultaneamente como fins em si." (KANT, 1995, p. 76)

Adiante nos seus estudos, o mesmo autor avalia:

No reino dos fins tudo tem ou um preço ou uma dignidade. Quando uma coisa tem preço, pode-se pôr em vez dela qualquer outra coisa como equivalente; mas quando uma coisa está acima de todo o preço, e, portanto, não permite equivalente então ela tem dignidade. [...] O que se relaciona com as inclinações e necessidades gerais do homem tem um preço venal; aquilo que, mesmo sem pressupor uma necessidade, é conforme a um certo gosto, isto é a uma satisfação no jogo livre e sem finalidade das nossas faculdades, anímicas, tem um preço de afeição ou de sentimento; aquilo, porém que constitui a condição só graças à qual qualquer coisa pode ser um fim em si mesma, não tem somente um valor relativo, isto é um preço, mas um valor íntimo, isto é, dignidade. (KANT, 1995, p. 76/77)

As lições de Immanuel Kant contribuem para aclarar a concepção que o obreiro, a sua mão de obra e o seu esforço humano, não podem jamais ser utilizados por aquele que explora o trabalho humano apenas com a finalidade voltada para o aumento de riquezas, a construção de patrimônio, a busca incessante de lucros etc. É venerável para a construção da ordem econômica constitucional, que o trabalho seja explorado em consonância com o seu fundamento na valorização do trabalho, proporcionando ao trabalhador condições de gozo para uma existência num contorno genuinamente digno.

A fim de impedir as situações de trabalho indigno, bom destacar a definição do que vem a ser trabalho digno, que pode ser compreendido como o direito universal basilar que precisa ser aperfeiçoado no referencial valorativo do conceito da dignidade da pessoa humana. (ROSENFIELD; PAULI, 2012, n.p.)

Nesses termos, o trabalho humano não pode ser explorado sob a violação da existência digna do obreiro; as regras constitucionais e a legislação específica que tratam da exploração e da prestação do trabalho devem ser respeitadas; os direitos absolutamente indisponíveis devem ser sopesados minimamente para que o trabalhador tenha sua dignidade resguardada.

Revista de Direito Brasileira | São Paulo, SP | v. 19 | n. 8 | p. 221 - 237 |Jan./Abr. 2018 
Ponderando o tema da indisponibilidade dos direitos Maurício Delgado acentua:

Absoluta será a indisponibilidade, do ponto de vista do Direito Individual do Trabalho, quando o direito enfocado merecer uma tutela de nível de interesse público, por traduzir um patamar civilizatório mínimo firmado pela sociedade política em um dado momento histórico. [...] a noção de indisponibilidade absoluta atinge, no contexto das relações bilaterais empregatícias (Direito Individual, pois), parcelas que poderiam, no contexto do Direito Coletivo do Trabalho, ser objeto de transação coletiva e, portanto, de modificação real. [...] Relativa será a indisponibilidade, do ponto de vista do Direito Individual do Trabalho, quando o direito enfocado traduzir interesse individual ou bilateral simples, que não caracterize um padrão civilizatório geral mínimo firmado pela sociedade política em um dado momento histórico. (DELGADO, 2007, p. 217/218)

Partindo dessa distinção, revela-se mais fácil a compreensão da importância de estabelecer aos direitos trabalhistas a indisponibilidade total desses, aplicada no sistema jurídico brasileiro, primado garantir ao obreiro um mínimo existencial no seu ambiente laboral - o direito basilar ao trabalho digno.

Considerar a terminologia "trabalho digno", é o mesmo que reconhecer o método do trabalho decente, compromisso assumido pelo governo brasileiro com a Organização Internacional do Trabalho - OIT em 2003, para a sua promoção em território nacional, consolidando no âmbito do trabalho humano, o princípio da dignidade e o seu fundamento na ordem econômica, o que remonta a ideia que o direito social ao trabalho digno, cuida necessariamente de um direito indisponível que deve ser preservado pelo Estado.

Gabriela Delgado traz um rol de direitos trabalhistas que podem ser considerados absolutamente indisponíveis:

Entende-se que os direitos trabalhistas de indisponibilidade absoluta estão previstos em três grandes eixos jurídicos, positivados pelo Direito do Trabalho brasileiro. Vale dizer que os eixos de proteção, a seguir analisados, são necessariamente complementares e interdependentes. [...] O primeiro eixo diz respeito aos direitos fixados pelas normas de tratados e convenções internacionais ratificadas pelo Brasil. O segundo eixo refere-se aos direitos fundamentais dos trabalhadores previstos no art. $7^{\circ}$ da Constituição da República de 1988. O terceiro eixo encontra-se positivado nas normas infraconstitucionais, por exemplo, na Consolidação das Leis Trabalhistas, que preceitua direitos de indisponibilidade absoluta no que tange a saúde e segurança no trabalho, identificação profissional e proteção contra acidentes do trabalho, entre outros. (DELGADO, 2006, p. 215)

Robustecendo a definição nuclear da dignidade da pessoa humana, insta ressaltar que cuida de um atributo essencial do ser humano e por isso quando o destaque é o trabalho digno, deve-se alcançar todos os indivíduos obreiros, compondo o direito de acesso ao trabalho, liberdade de sua escolha, remuneração justa, jornada de trabalho humana e ainda o direito de associação dos obreiros, formando assim uma importância abotoada de trabalho digno ou no que compreende a doutrina, de trabalho decente. José Cláudio Monteiro de Brito Filho adverte que: "[...] menos que isso é sujeitar o trabalhador a condições de trabalho que estão abaixo do necessário para que seja preservada sua dignidade.” (BRITO FILHO, 2004, p. 61)

$\mathrm{O}$ fato é que independente da terminologia adotada - trabalho digno ou decente -, o que importa são as condições em que o trabalho é realizado, devendo respeitar a digna existência do obreiro, tomando por base a valorização do seu trabalho, possível a partir da hermenêutica 
jurídica sob a égide do Texto Constitucional e das regras do Direito do Trabalho; esse compasso viabiliza condições para que o trabalhador alcance o aspecto da dignidade enquanto indivíduo e parte da comunidade social, dando aspectos mais concretos para a concretização da ordem econômica num formato equilibrado - em que trabalhador e quem explora a sua mão de obra, detenham condições paritárias no que concerne as vantagens do resultado do trabalho humano.

\section{A ORDEM CONSTITUCIONAL ECONÔMICA DE 1988}

Até aqui percebeu-se uma interação entre a ordem jurídica e a econômica, pois a produção, a circulação dos bens produzidos e o consumo desses não poderiam alargar-se em prol das necessidades sociais e do próprio Estado, sem uma normatização mínima.

A ciência do Direito na pretensão de determinar uma grandeza jurídica à ordem econômica, cuidou de estruturar a forma como a ação produtiva deve se organizar e movimentar, definindo a política econômica estatal.

Citada regulação, traduz a passagem do capitalismo clássico ou puro - característica do Estado Liberal -, para o modelo capitalista com um viés social - figura do intervencionismo do Estado Social.

Após a Constituição do México de 1917 construir a dimensão jurídica da ordem econômica, conforme é reconhecida hoje, sobrevinda da Constituição de Weimar de 1919 e no Estado Brasileiro pela Constituição de 1934, a Constitucional da República de 1988 disciplinou a Ordem Econômica e Financeira no Título VII, composto dos artigos 170 a 192. (MATSUSHITA, 2007, p. 41/45)

Eros Roberto Grau expõe a sua defesa sobre a Ordem Econômica:

[...] a ordem econômica, ainda que se oponha a ordem jurídica, é usada para referir-se uma parcela da ordem jurídica, que compõe um sistema de princípios e regras, compreendendo uma ordem pública, uma ordem privada, uma ordem econômica e uma ordem social [...]. (GRAU, 2004, p. 51)

André Ramos Tavares também pondera sobre a ordem econômica ser considerada uma ordem jurídica: “[...] a expressão de um certo arranjo econômico, dentro de um específico sistema econômico, preordenado juridicamente. É a sua estrutura ordenadora, composta por um conjunto de elementos que confronta um sistema econômico.” (TAVARES, 2006, p. 81)

Por outro lado, Vital Moreira a partir das notas de Eros Grau, dirige o entendimento de que a ordem econômica não possui um único sentido, mas três: primeiramente é considerada uma forma concreta de ser no sentido empírico de uma determinada economia concreta, ou seja, cuida do termo que traduz a relação entre fatores econômicos concretos que exprime a realidade de uma articulação do contexto econômico como fato; num segundo plano revela o conjunto de todas as normas independente da natureza, desde que respeitem a regulação do comportamento dos sujeitos econômicos e o sistema normativo/sociológico da ação econômica; e por derradeiro, significa a própria ordem jurídica da economia. (MOREIRA apud GRAU, 2004, p. 57/58)

$\mathrm{O}$ modelo econômico liberal, asilado por aquele Estado inerte à regulamentação das relações sociais, dá lugar ao modelo econômico respaldado pela intervenção estatal, em que o Estado passa a ser agente regulador das atividades econômicas e das relações de trabalho. (MATTOS, 2006, n.p.)

Sobre o intervencionismo estatal no Direito Econômico, a compreensão é variável e, portanto, independente de qual seja o nível de intervenção do Estado, o seu papel é proteger a sociedade de abusos do poder econômico também no refere a exploração da mão de obra humana, mormente as ações desenfreadas na busca por lucro e na produção de riquezas despreocupada com as condições do trabalho digno. 
Por tais argumentos, é aceitável sustentar que a Constituição da República de 1988 ao se preocupar distintamente com a ordem econômica, trazendo-a em um contexto específico no bojo do seu texto, atentou em condicionar comando ao instituto, confirmando suas bases, finalidades e princípios, em consonância aos ditames da justiça social, firmando, por conseguinte, a funcionalidade da ordem econômica operando com as garantias constitucionais de forma justa e equilibrada para o tomador e o prestador da mão de obra humana.

\section{A GRAVITAÇÃO DA VALORIZAÇÃO DO TRABALHO HUMANO NA ORDEM ECONÔMICA CONSTITUCIONAL}

A propósito da disposição da valorização do trabalho humano na Carta Constitucional, apresentado como um dos fundamentos da ordem econômica, percebe-se uma importância do seu papel ao lado do rol de princípios estabelecidos no artigo 170, agregando um cenário jurídico social e transformando o formato como o sistema econômico vinha sendo tratado anterior ao Texto Constitucional de 1988, corroborando para a noção da gravitação desse sistema capitalista para um cenário destinado ao senso mais social.

A respeito dos modelos de capitalismo citados nessa pesquisa - puro ou clássico e social -, plausível apresentar a distinção entre eles, como se demonstrará a seguir:

O capitalismo puro ou clássico refere-se ao sistema exercido sem qualquer controle estatal, ou seja, o Estado abjura ingerência na economia e nas relações de trabalho, existe somente a presença do agente que explora a mão de obra e do que é explorado, esse sob o domínio daquele. Já o modelo vigente - capitalismo social - mais reconhecido pela doutrina como liberal, é percebido sob a pauta de um Estado intervencionista, com a finalidade de garantir à sociedade uma proteção contra abusos do poder econômico. (BRESSER-PEREIRA, 2005, n.p.)

Esclarecido esse ponto, José Afonso da Silva adverte sobre a ordem econômica: “[...] consubstanciada em nossa Constituição vigente, é uma forma econômica capitalista, porque ela se apoia inteiramente na apropriação privada dos meios de produção e na iniciativa." (SILVA, 2001, p. 764)

As considerações de José Afonso da Silva contribuem para o entendimento de que a Carta da República de 1988, ao assinalar a ordem econômica baseada nos meios de produção e na iniciativa, traz um formato econômico nacional edificado num sistema capitalista e que uma vez o Estado possuindo o dever de intervir nas relações de trabalho e na própria economia, sanciona a afirmação apresentada nessa pesquisa, ou seja, que em território nacional vigora um sistema político e econômico capitalista liberal.

Raul Machado Horta apresentado por Alexandre de Moraes revela:

[...] que o texto constitucional na ordem econômica está impregnada de princípios e soluções contraditórias. Ora reflete um rumo do capitalismo liberal, consagrando os valores fundamentais desse sistema ora avança no sentido de intervencionismo sistemático e do dirigismo planificador, com elementos socializadores. (HORTA apud MORAES, 2008, p. 796)

Estabelecida como um dos fundamentos da ordem econômica, a valorização do trabalho humano encontra sua previsão normativa no caput do artigo 170 da Carta Magna, juntamente com a livre iniciativa, garantindo como sustentáculo a própria ordem econômica. Contudo, também com a roupagem de valores sociais do trabalho, se apresenta na letra do Texto Constitucional como um dos fundamentos da República Federativa do Brasil.

Ponderando a valorização do trabalho, José Joaquim Gomes Canotilho diz tratar-se de um princípio político constitucionalmente conformador (CANOTILHO, 2006, p. 201), que pode ser traduzido com base naqueles princípios constitucionais que carregam sentimentos de valoração política fundamental do legislador constituinte, fruto da concepção política 
predominante dentro da assembleia que elaborou o hodierno Texto Constitucional, ponderando os princípios que deliberam a forma do Estado e do governo, organizando até mesmo o regime político e econômico. (CADEMARTORI; MIRANDA, 2016, n.p.)

Manoel Gonçalves Ferreira Filho garante que: “[...] a valorização do trabalho é princípio sublinhado pelo constituinte dentro da linha firmada pela doutrina social da igreja, como sendo um valor cristão." (FERREIRA FILHO, 2007, p. 361)

Tal como o próprio Direito, a valorização do trabalho humano trata-se de um conhecimento que não pode ser glosado de forma fechada e desligada do sistema jurídico; igualmente, deve ser lida no contexto constitucional como um todo, considerando os preceitos da dignidade do obreiro e os demais princípios que compõe a ordem econômica (artigo 170 da $\mathrm{CRF} / 88$ ). A confirmação desse Estado responsável, dá-se pela interferência nas questões pautadas diretamente com a dignidade e o sustento do sujeito de direitos e igualmente da própria extensão atingida patrimonialmente através da exploração do seu trabalho, isto é, dos resultados da prestação do labor humano.

Meditando ainda sobre a valorização do trabalho e sua caracterização principiológica, Eros Roberto Grau destaca que: "[...] em uma sociedade capitalista moderna, peculiariza-se na medida em o trabalho passa a receber proteção não meramente filantrópica, porém politicamente racional." (GRAU, 2004, p. 198)

Ao tecer tal consideração, o autor explana o valor do sentido fundamental da valorização do trabalho humano para ordem econômica constitucional, com a intenção de avigorar as ações interventivas do Estado para garantir a dignidade da pessoa humana também no pilar econômico da teoria da sustentabilidade (ELKINGTON, 2012, p. 20.), garantindo direitos ao obreiro - que emprega sua mão de obra humana como um fator social de produção na construção da ordem econômica e consequentemente da sociedade brasileira, atuando com mais equilíbrio, ao passo que aquele que empreende as custas do trabalho humano não o possa fazer sem a preservação das condições dignas de prestação do trabalho. Concluindo que o trabalho é um fator social de produção.

Nesse sentido, Nagib Slaib Filho revela: “[...] porém ele está muito além da necessidade econômica de suprir as necessidades materiais - é uma necessidade, inerente à natureza humana e ao instituto da autopreservação e progresso pessoal." (SLAIB FILHO, 2006, p. 702)

A valorização do trabalho humano surge então para contestar as práticas de exploração do trabalho, a produção de riquezas e a busca desenfreada por lucros (AMORIM, 2013, n.p.). Deste modo, a consagração imposta no artigo 170 da Lei Maior, da valorização do trabalho humano como um fundamento, atribui função elementar para o desempenho do Estado Democrático de Direito, que deve se encarregar do seu papel interventor, abonando a salvaguarda de uma vida humana digna a todos, seguindo os ditames da justiça social.

A propósito do que vem sendo debatido no presente artigo, sobre a necessidade de se equilibrar a prestação do labor e a sua exploração - justapondo valores dignos para a ordem econômica e a própria sociedade -, importante relevar a parcela de responsabilidade da empresa e essa social, ou seja, o compromisso de adequar a atuação empresarial em prol somente do vigor econômico, mas também amparando suas razões na ordem social, que sob a atenção do Estado e atuando conjuntamente com esse, tendem a operar em prol da valorização do trabalho humano.

Max Weber a respeito do caráter do ambiente da empresa revela que:

A empresa nos dias atuais é um imenso cosmos, no qual o indivíduo nasce, e que se apresenta a ele, pelo menos como indivíduo, como uma ordem de coisa inalterável, na qual ele deve viver. Obriga o indivíduo, na medida em que ele é envolvido no sistema de relações de mercado, a se conformar às regras de ação capitalistas. O fabricante que permanentemente se opuser a estas normas será economicamente eliminado, tão inevitavelmente quanto trabalhador que não 
puder ou não quiser adaptar-se a elas será lançado à rua sem trabalho. (WEBER, 2000, p. 34)

A empresa também deve ser considerada como um ambiente paralelo que viabiliza o trabalhador na descoberta de chances de expandir suas aptidões numa oportunidade para o alcance de qualificação. A responsabilidade social nesse reservado da valorização do trabalho humano, pode ser evidenciada no momento em que são admitidos trabalhadores desqualificados com o objetivo de dar oportunidades de qualificação e adequação para um trabalho peculiar, mais aprimorado que até então não havia aptidão para a sua realização. Esse arranjo empresarial é ponderado como um revés diligente na valorização do trabalho humano - adequando condições dignas de trabalho a todos os trabalhadores, revigorando efeitos em prol da busca do pleno emprego que atinge consequentemente, o patamar da dignidade do trabalhador.

Distintas são as responsabilidades sociais da empresa, entre elas a primazia de proceder com uma gestão que efetivamente cumpra o fundamento da valorização do trabalho humano da ordem econômica, conferindo condições dignas na prestação do trabalho do indivíduo obreiro, de modo que esse indivíduo atinja seu aspecto de dignificação no ambiente laboral e o ente empresarial logre êxito na sua responsabilidade social tanto no desígnio da qualidade de vida dos trabalhadores como na construção das ordens econômica e social, num padrão justo e equilibrado. (LIMA, 2009, p. 139)

Visualizando a responsabilidade social da empresa e a sua relação com o fundamento da valorização do trabalho humano, percebe-se que houve por parte do constituinte uma preocupação em tornar a norma eficaz e passível de concretude; igualmente quanto ao processo de aplicação do método da hermenêutica constitucional, que com subsídio no artigo $3^{\circ}$, inciso I, apontado como um dos objetivos fundamentais - tem por premissa construir uma sociedade solidária e livre justa. Neste sentido, cumpre refletir que o próprio artigo 170, ao fundar a ordem econômica na valorização do trabalho humano, revitaliza a acepção da busca pelo pleno emprego como um dos seus princípios, então disposto no inciso VIII.

\subsection{O Ativismo Judicial}

Em que pese o modelo intervencionista do Estado e o ora destinado à ação empresarial no tocante a responsabilidade social da empresa, nem sempre a garantia da valorização do trabalho humano como um dos fundamentos da ordem econômica, tem sua eficácia atingida conforme os ditames constitucionais e nesses casos é necessário que o ativismo judicial opere com a incumbência de garantir a premissa dos valores contidos no Texto Constitucional, validando-os a partir de decisões judiciais.

Logo, o ativismo judicial destaca-se por ser o fenômeno jurídico resultado da postura proativa desempenhada pelo Poder Judiciário frente os casos concretos, que tem por finalidade buscar a realização da conformidade dos problemas reais apresentados com a letra da lei.

Sobre o tema específico, o qual estar-se debatendo - a valorização do trabalho humano na ordem econômica constitucional -, o julgado a seguir revela a atividade econômica como premissa legitimada em um sistema capitalista de produção, que está condicionado aos ditames do artigo 170 da Carta da República:

RECURSO DE REVISTA EM FACE DE DECISÃO PUBLICADA ANTES DA VIGÊNCIA DA LEI No 13.015/2014. SOCIEDADE DE ECONOMIA MISTA. MOTIVAÇÃO DA DISPENSA. REINTEGRAÇÃO NO EMPREGO. As empresas públicas e as sociedades de economia mista possuem personalidade jurídica de direito privado e integram a Administração Pública Indireta. Assim, nos termos do art. 37, caput, da Constituição Federal, submetem-se aos princípios da legalidade, impessoalidade, moralidade, publicidade e eficiência. 
Ademais, a Carta Magna (art. 37, II) dispõe, também, que a investidura em cargo ou emprego público depende de aprovação prévia em concurso. Diante disso, a dispensa de empregados públicos deve ser devidamente motivada, em face do princípio constitucional da motivação (art. 37, caput, da Constituição Federal). Nesse mesmo sentido decidiu o Plenário do STF, ao julgar o Recurso Extraordinário $\mathrm{n}^{\circ}$ 589.998, que se aplica em especial à hipótese em que a empresa não atua em regime concorrencial. Isso porque o exercício da atividade econômica, premissa legitimada em um sistema capitalista de produção, está condicionado pelo artigo 170 da Constituição à observância dos princípios nele enumerados, dentre os quais se incluem a valorização do trabalho humano, a existência digna, de acordo com a justiça social (caput), e a função social da propriedade (inciso III), este último perfeitamente lido como função social da empresa. Nas palavras de Eros Roberto Grau, ao se referir à vinculação entre os artigos 170 e os princípios enumerados no art. $1^{\circ}$ da Constituição: 'A perfeita compreensão dessa obviedade é essencial, na medida em que informará a plena compreensão de que qualquer prática econômica (mundo do ser) incompatível com a valorização do trabalho humano e com a livre iniciativa, ou que conflite com a existência digna de todos conforme os ditames da justiça social, será adversa à ordem constitucional. Será, pois, inconstitucional'. Recurso de revista de que não se conhece. (BRASIL, Tribunal Superior do Trabalho, DEJT $31 / 03 / 2015)$

O ativismo judicial realizado pela Corte do Tribunal Superior do Trabalho nesse julgado colabora com as expectativas propostas nessa pesquisa proposta, no sentido de apontar que o exercício da atividade econômica está condicionado à observância de uma gama de princípios constitucionais, incluindo-se entre eles a valorização do trabalho humano, daí revelar com obviedade a sua raiz essencial para o funcionamento acertado para a ordem econômica, ao passo que a prática econômica conflitante com o fundamento da valorização do trabalho humano, será verificada como avessa à ordem constitucional e, portanto, pode ser considerada inconstitucional.

A jurisprudência a seguir, assegura também a importância da valorização do trabalho humano na celebração de um contrato de trabalho, pelo qual se formaliza através do direito das obrigações, contando com a participação solidária das partes - empregado e empregador -com vias a sintetizar a garantia de uma existência digna. É o que decidiu o Tribunal Regional do Trabalho da Nona Região:

TRT-PR-10-05-2011 RESCISÃO INDIRETA - ASSÉDIO MORAL - FUNÇÃO SOCIAL DO CONTRATO - SOLIDARISMO - BOA-FÉ OBJETIVA - LIVRE INICIATIVA - VALORIZAÇÃO DO TRABALHO HUMANO - Ao lado das obrigações principais do contrato de trabalho (tal como pagamento de salário, depósitos do FGTS, etc, por parte do empregador e prestação de serviços, dever de fidelidade pelo empregado), subsistem obrigações acessórias, deveres colaterais de observância obrigatória, pois fulcrados nos princípios da função social do contrato, boa fé objetiva e no princípio do solidarismo contratual. O contrato de trabalho visto sob o viés do direito das obrigações deve ser analisado como sistema dinâmico, em que ambas as partes contratantes solidarizam esforços para uma consecução comum, com vistas, de um lado, na valorização do trabalho humano e, em outro, na livre iniciativa, mas tendo como norte sempre a busca da garantia de uma existência digna ( $\mathrm{CF}$, artigo170). A partir do momento em que há a prática do assédio moral, esse aspecto obrigacional do solidarismo contratual dá espaço para um despotismo que deve ser arredado, mediante mecanismos jurídicos de compensação. Rescisão indireta reconhecida. (BRASIL, Tribunal Regional do Trabalho da 9a Região, RO 76352007663905 PR 7635-2007-663-9-0-5) 
O valor do ativismo judicial também é averiguado nos casos em que a ação do Poder Judiciário é necessária para dirimir problemas oriundos das ações perpetradas pelos entes sindicais, que exercendo o direito constitucional da formulação de acordos coletivos de trabalho (art. $7^{\circ}, \mathrm{XXVI}, \mathrm{CRF} / 88$ ), fazem constar cláusulas que mitigam direitos trabalhistas. No caso $s u b$ examine, o Tribunal Superior do Trabalho operou para a solução de caso que tinha como centro de discussão, cláusula que previa expressiva redução do percentual destinado ao pagamento do adicional de periculosidade, limitando-o a apenas 13\% do salário base de classe:

RECURSO ORDINÁRIO. AÇÃO ANULATÓRIA. ACORDO COLETIVO DE TRABALHO. CLÁUSULA NONA. ADICIONAL DE PERICULOSIDADE. PAGAMENTO PROPORCIONAL. IMPOSSIBILIDADE. DIREITO REVESTIDO DE INDISPONIBILIDADE ABSOLUTA. DIGNIDADE DA PESSOA HUMANA. VALORIZAÇÃO DO TRABALHO HUMANO. CONSTITUIÇÃO FEDERAL, ARTS. $1^{\circ}$, III, 7º, -CAPUT-, XXII, XXIII E 170. CONVENÇÃO 155 DA OIT. CANCELAMENTO DO ITEM II DA SÚMULA 364/TST. Pelo princípio da adequação setorial negociada as normas autônomas juscoletivas construídas para incidirem sobre uma certa comunidade econômicoprofissional podem prevalecer sobre o padrão geral heterônomo justrabalhistas desde que respeitados certos critérios objetivamente fixados. São dois esses critérios autorizativos: a) quando as normas autônomas juscoletivas implm [sic.] um padrão setorial de direitos superior ao padrão geral oriundo da legislação heterônoma aplicável; b) quando as normas autônomas juscoletivas transacionam setorialmente parcelas justrabalhistas de indisponibilidade apenas relativa (e não de indisponibilidade absoluta). Por sua vez, o ordenamento jurídico, notadamente a partir da Constituição Federal de 1988, expressamente elegeu a saúde como direito social, garantindo proteção, bem-estar e integridade física aos trabalhadores. Note-se que a CF estipula, como direito dos trabalhadores, a redução dos riscos inerentes ao trabalho, por meio de normas de saúde, higiene e segurança (art. $7^{\circ}$, XXII). Essa inclusive é a exegese da Convenção $\mathrm{n}^{\circ} 155$ da OIT, ratificada pelo Brasil em 18.05.1992, que expressamente estabelece a adoção de medidas relativas à segurança, à higiene $\mathrm{e}$ ao meio ambiente do trabalho. Nessa diretriz, o Pleno do TST, na sessão do dia 24.5.2011, cancelou o item II da Súmula 364 do TST, que permitia a fixação do adicional de periculosidade em percentual inferior ao legal e proporcional ao tempo de exposição ao risco, desde que pactuado em acordo ou convenção coletivos. Nesse aspecto, por se tratar o adicional de periculosidade de medida de saúde e segurança do trabalho, garantido por norma de ordem pública (CLT, art. 193, $\S 1^{\circ}$ ), é vedada, pelo ordenamento jurídico pátrio, qualquer mitigação, ou seja, não podem o ACT, a CCT ou a sentença normativa flexibilizar o percentual em patamar inferior ao legal, proporcionalmente ao tempo de exposição ao risco. Na hipótese dos autos, o parágrafo primeiro da cláusula nona do Acordo Coletivo de Trabalho elide direito revestido de indisponibilidade absoluta dos trabalhadores, ao estipular o pagamento do adicional de periculosidade no valor equivalente a $13 \%$ do valor do salário base. A norma coletiva, fixada nesses termos, não ser acolhida. Recurso ordinário desprovido. (BRASIL, Tribunal Superior do Trabalho, RO: 520004520095070000 5200045.2009.5.07.0000)

Na legislação trabalhista vigente, no momento que um acordo coletivo traz em seu bojo cláusula que estipula percentual de $13 \%$ (treze por cento) sobre o salário base dos empregados a título de adicional de periculosidade, o preceito coletivo fere a base legal mínima de Direitos Sociais balizada no artigo $7^{\circ}$ da Carta da República e a própria dignidade dos trabalhadores, bem 
como o ora garantido por norma de ordem pública (art. 193, $\S 1^{\circ}$, da CLT $^{2}$ ), sendo, portanto, vedado pelo ordenamento jurídico pátrio qualquer normatização que tenha por finalidade a mitigação de direitos positivados, ou seja, não se admite acordos e convenções coletivas e/ou sentenças normativas que atuem para flexibilizar o percentual legal em patamar inferior, proporcionalmente ao tempo de exposição ao risco. A ação sindical nesse caso específico, careceu do ativismo judicial para que fosse tutelado o interesse público, restaurando a ordem civilizatória mínima para a sociedade democrática, de ter garantida a própria dignidade da pessoa humana e a valorização mínima deferível ao trabalho (arts. $1^{\circ}$, III e 170, caput, da CRF/88).

As decisões colacionadas aqui servem para ratificar a defesa de que o ativismo judicial é a instância última disponível ao indivíduo trabalhador, que tem por conotação a efetividade na revelação da valorização do trabalho humano na ordem econômica constitucional, isso em razão da insuficiência da ação estatal em atender os anseios dos obreiros na prestação do trabalho humano, realizando concretamente os direitos e garantias, essencialmente a dignidade, assegurando o cerceamento de práticas de exploração de mão de obra humana na forma indigna, produção de riquezas e a busca desenfreada por lucros. (TEIXEIRA, 2012, n.p.)

De mais a mais, o imperioso não é estabelecer uma definição dogmática para o ativismo judicial, mas sim percebê-lo como fenômeno destinado a relevar a hermenêutica jurídica da valorização do trabalho humano enquanto fundamento da ordem econômica, destacando a nova roupagem do sistema capitalista do Estado Brasileiro, pelo qual a intervenção estatal na economia e nas relações de trabalho revela-se essencial no atributo de proteger o indivíduo no seu valor intrínseco da pessoa humana, sua dignidade, rematando as ordens econômica e social num funcionamento equilibrado, justo e solidário entre elas.

\section{CONSIDERAÇÕES FINAIS}

O constituinte preocupou-se em formalizar um texto que tivesse por premissa a dignidade da pessoa humana e no âmbito da ordem econômica, fundamentou-a através da valorização do trabalho, garantindo dessa forma aos trabalhadores direitos mínimos, proibindo todo tipo de discriminação e estabelecendo uma ordem econômica que tivesse como fundamento e finalidade a própria valorização do trabalho humano.

Destarte, ao implantar na Constituição da República - caput do artigo 170 - a valorização do trabalho humano como um dos fundamentos da ordem econômica, o escopo do constituinte foi harmonizar um aspecto social ao sistema capitalista no Estado Brasileiro. A economia revela-se responsabilidade estatal, cujo dever é de regular e destinar atenção às ações empresariais para que atuem num contexto responsável, primando pelo equilíbrio e equidade na exploração das relações de trabalho para o reflexo nas sociais, assegurando-se, portanto, a integridade do social dentro da ordem econômica.

A ordem econômica ponderada sob o prisma da hermenêutica jurídica leva em consideração a valorização do trabalho humano, como meio de afiançar a essência que o trabalhador merece reconhecimento como um ser não só individual, mas também social, empossado de finalidades, que juntando com os outros agentes econômicos, constituem um ambiente econômico social e solidário.

\footnotetext{
2 Art. 193. São consideradas atividades ou operações perigosas, na forma da regulamentação aprovada pelo Ministério do Trabalho e Emprego, aquelas que, por sua natureza ou métodos de trabalho, impliquem risco acentuado em virtude de exposição permanente do trabalhador a:

[...]

$\S 1^{\circ}$ - O trabalho em condições de periculosidade assegura ao empregado um adicional de $30 \%$ (trinta por cento) sobre o salário sem os acréscimos resultantes de gratificações, prêmios ou participações nos lucros da empresa. [...]
} 
Nessa linha, o artigo primou tratar a importância do papel interventivo do Estado Brasileiro para a solidificação de uma ordem econômica mais equilibrada, resguardando o papel venerado da empresa de operar sob o aspecto da responsabilidade social como um instrumento ativo que também tende a proporcionar condições de dignidade aos indivíduos trabalhadores nos seus ambientes de trabalho. E para os casos de ineficácia da disposição da norma, o trabalho destacou o ativismo judicial como o fenômeno jurídico disponível no ordenamento, capaz para operar em prol de obter resultados mais positivos, que sem demonizar e/ou extinguir a sustentação da ordem econômica, preocupa-se também com o pilar social, para que os benefícios da exploração da mão de obra não sejam desfrutados apenas pela classe empresarial.

Arrematando, percebe-se a relevância de apontar a acuidade do ativismo judicial na revelação da valorização do trabalho humano na ordem econômica constitucional, principalmente nesse processo de mudança da norma trabalhista, que tende a funcionar como o instrumento que busca solucionar casos práticos para o estabelecimento do equilíbrio da prestação e exploração da mão de obra humana, ao passo que toda e qualquer prática econômica conflitante com esse fundamento, seja julgada como avessa à ordem constitucional, recebendo consequentemente o ônus da inconstitucionalidade, resultando assim na devolução às ordens econômica e social, a eficácia enquadrada nas cláusulas principiológicas apresentadas pela Carta da República.

\section{REFERÊNCIAS BIBLIOGRÁFICAS}

ALEXY, Robert. Teoría de los derechos fundamentales. Tradução de Ernesto Garzón Valdés. Madrid: Centro de Estudios Constitucionales, 1993.

AMORIM, Henrique. O tempo de trabalho: uma chave analítica. Sociedade e Estado. v. 28, n. 3, Brasília, $\quad$ Sept./Dec. 2013. Disponível em: <http://www.scielo.br/scielo.php?script=sci_arttext\&pid=S0102-69922013000300003>. Acesso 06 set. 2016.

ÁVILA, Humberto. Teoria dos princípios: da definição à aplicação dos princípios jurídicos. 4. ed. São Paulo: Malheiros, 2004.

BRASIL. Constituição da República Federativa do Brasil de 1988. Disponível em: <http://www.planalto.gov.br/ccivil_03/constituicao/constituicaocompilado.htm>. Acesso em 11 set. 2016.

Decreto-lei n. ${ }^{\circ}$ 4.657, de 4 de setembro de 1942: Lei de Introdução às normas do

Direito Brasileiro. Disponível em: <http://www.planalto.gov.br/ccivil_03/decretolei/Del4657compilado.htm>. Acesso em 11 set. 2016.

Lei n. ${ }^{\circ}$ 5.172, de 25 de outubro de 1966: Dispõe sobre o Sistema Tributário Nacional e institui normas gerais de direito tributário aplicáveis à União, Estados e Municípios. Disponível em: <http://www.planalto.gov.br/ccivil_03/leis/15172.htm>. Acesso em 11 set. 2016.

Tribunal Regional do Trabalho da Nona Região. RO 76352007663905 PR 7635-2007663-9-0-5. Relator: ANA CAROLINA ZAINA, 2A. TURMA, Data de Publicação: 10/05/2011.

Tribunal Superior do Trabalho. RO: 520004520095070000 52000-45.2009.5.07.0000. Relator: Mauricio Godinho Delgado, Data de Julgamento: 13/08/2012. 
Tribunal Superior do Trabalho. RR: 14266320115010081. Relator: Cláudio Mascarenhas Brandão, Data de Julgamento: 25/03/2015, $7^{\text {a }}$ Turma, Data de Publicação: DEJT $31 / 03 / 2015$.

BRESSER-PEREIRA, Luiz Carlos,. Capitalismo dos técnicos e democracia. Revista Brasileira de Ciências Sociais. v. 20, n. 59, São Paulo, Out. 2005. Disponível em: <http://www.scielo.br/scielo.php?script=sci_arttext\&pid=S0102-69092005000300009>. Acesso em: 09 set. 2016.

BRITO FILHO, José Cláudio Monteiro de. Trabalho decente. Análise jurídica da exploração do trabalho - trabalho forçado e outras formas de trabalho indigno. São Paulo: LTr, 2004.

CADEMARTORI, Sergio Urquhart; MIRANDA, José Alberto Antunes de. Democracia, Constituição e Relações Exteriores: o papel do Direito e da Cidadania no Contexto do Novo Constitucionalismo Latino-Americano. Sequência (Florianópolis). n. 72, Florianópolis, Jan./Apr. 2016. Disponível em: <http://www.scielo.br/scielo.php?script=sci_arttext\&pid=S217770552016000100093>. Acesso em: 09 set. 2016.

CAMARGO, Ricardo Zagallo. Responsabilidade social das empresas: formações discursivas em confronto. 2009. 431 f. Tese (Doutorado em Ciências da Comunicação). Universidade de São Paulo, São Paulo.

CANOTILHO, José Joaquim Gomes. Direito constitucional e teoria da constituição. 7. ed. Coimbra: Almedina, 2006.

DELGADO, Gabriela. Direito fundamental ao trabalho digno. São Paulo: LTr, 2006.

DELGADO, Maurício. Curso de direito do trabalho. 6. ed. São Paulo: LTr, 2007.

ELKINGTON, John. Sustentabilidade: canibais com garfo e faca. Tradução de Laura Prades Veiga. São Paulo: M.Books do Brasil Editora Ltda., 2012.

FERREIRA FILHO, Manoel Gonçalves. Curso de direito constitucional. 33. ed. São Paulo: Saraiva, 2007.

GRAU, Eros Roberto. A ordem econômica na Constituição de 1988 (interpretação e critica). 9. ed. rev. e atual. São Paulo: Malheiros, 2004.

KANT, Immanuel. Fundamentação da metafísica dos costumes. Tradução de Paulo Quintela. Lisboa: Edições 70, 1995.

LEDUR, José Felipe. A realização do direito ao trabalho. Porto Alegre: Sérgio Antônio Fabris Editor, 1998.

LIMA, Maria José de Oliveira. A responsabilidade social e o serviço social nas organizações empresariais. São Paulo: Editora UNESP; São Paulo: Cultura Acadêmica, 2009. 240 p. Disponível em: 〈http://books.scielo.org/id/cbyx4/pdf/lima-9788579830372-04.pdf〉. Acesso em 08 set. 16. 
MATSUSHITA, Thiago Lopes. Análise reflexiva da norma matriz da ordem econômica. 2007. 173 f. Dissertação (Mestrado em Direito). Pontifícia Universidade Católica de São Paulo, São Paulo.

MATTOS, Paulo Todescan Lessa. A formação do estado regulador. Novos estudos - CEBRAP. n. 76, nov. 2006, São Paulo. Disponível em: <http://www.scielo.br/scielo.php?script=sci_arttext\&pid=S0101-33002006000300007>. Acesso em 09 set 2016.

MENEZES, Franciane Cristina de. O Serviço Social e a "responsabilidade social das empresas": o debate da categoria profissional na Revista Serviço Social \& Sociedade e nos CBAS. Serviço Social \& Sociedade. n. 103, São Paulo, July/Sept. 2010. Disponível em: $<$ http://www.scielo.br/scielo.php?script=sci_arttext\&pid=S0101-66282010000300006>. Acesso em 08 set. 2016.

MORAES, Alexandre de. Direito constitucional. 23. ed. São Paulo: Atlas, 2008.

ROSENFIELD, Cinara L.; PAULI, Jandir. Para além da dicotomia entre trabalho decente e trabalho digno: reconhecimento e direitos humanos. Caderno CRH. v. 25, n. 65, Salvador, May/Aug. $2012 . \quad$ Disponível em: <http://www.scielo.br/scielo.php?script=sci_arttext\&pid=S0103-49792012000200009>. Acesso em 27 set. 2016.

SARLET, Ingo Wolfgang. Dignidade da pessoa humana e direitos fundamentais na constituição federal de 1988. 5. ed. Porto Alegre: Livraria do Advogado, 2007.

SILVA, José Afonso. Curso de direito constitucional positivo. 19. ed. rev. atual. e ampl. São Paulo: Malheiros, 2001.

SLAIB FILHO. Nagib. Direito constitucional. 2. ed. Rio de Janeiro: Forense, 2006.

SOUZA, Maria Cristina Cacciamali de. Mercado de trabalho: abordagens duais. Revista de Administração de Empresas. v. 18, n. 1, São Paulo, Jan./Mar. 1978. Disponível em: <http://www.scielo.br/scielo.php?script=sci_arttext\&pid=S0034-75901978000100006>. Acesso em 06 set. 2016.

TAVARES, André Ramos. Direito constitucional econômico. 2. ed. rev. e atual. São Paulo: Método, 2006.

WEBER, Max. A ética protestante e o espírito do capitalismo. 15. ed. São Paulo: Pioneira, 2000. 